\title{
Decolonialidade se faz em/com Quilombos
}

\author{
Decoloniality is done in / with Quilombos
}

\author{
Prof $^{\circ}$ Dr. Eduardo Oliveira \\ Miranda \\ Universidade Estadual de Feira \\ de Santana (UFES) \\ eduardomiranda48@gmail.com
}

Recebido em: 07/09/2020

Aceito em: 26/01/2021

\section{Resumo}

O artigo teve a sua sistematização durante a pandemia da Covid-19, período no qual o autor sentiu a necessidade de escrever sobre suas experiências a partir da abordagem decolonial. Trata-se uma escrita que mescla memórias, afetos e que tem os suleamentos com a seguinte problemática: como o encontro entre um corpo-território-educador-gay e um corpo-território-educanda-sapatão-preta pode criar um giro decolonial aquilombado? Apresenta-se um olhar sobre as colonialidades que fundamentam a estrutura da universidade brasileira e como um giro decolonial aquilombado pode provocar desobediências epistêmicas.

Palavras-chave: decolonialidade, aquilombar, corpo-território.

\section{Abstract}

The article was systematized during the Covid-19 pandemic, a period in which the author felt the need to write about his experiences based on the decolonial approach. It is a piece of writing that mixes memories, affections and that has the strangeness with the following problem: how can the encounter between a body-territory-educator-gay and a body-territory-educanda-sapatoo-negra create a decolonial spin? A look at the colonialities that underlie the structure of the Brazilian university is presented, and how a sloping decolonial turn can cause epistemic disobediences.

Keywords: decoloniality, aquilumbar, body-territory. 


\section{para reabrir caikas}

Decido, durante a pandemia da Covid-19, escrever sobre questões que afetam a minha existência, desde o campo subjetivo e/ou pelo compasso das coletividades estruturantes e estruturais. Nesse movimento, encontro algumas caixas com diversos livros do período que lecionava na educação básica, por onde estive por quase cinco anos na condição de professor contratado e em seguida, concursado. Ao abrir uma das caixas, me deparo com livros didáticos de História e Geografia, começo a folhear as páginas, observar as imagens, interpretar os textos. Decido guardar os livros e fechar as caixas.

Voltei aos livros da educação básica após seis anos distantes deles. Sou um outro corpo-território (MIRANDA, 2019). Passei por diversas experiências as quais me levaram a desterritorializar o meu corpo-território e reterritorializar uma outra existência corporal. As lentes de leitura do mundo foram alargadas, rachadas e, sobretudo, constrangidas. Sim, aprendi com a Pedagogia do Constrangimento a compreender um pouco mais sobre quem eu sou, ou ainda mais, sobre como as colonialidades do poder (QUIJANO, 2007), do gênero e da sexualidade (LUGONES, 2008) pautaram a minha constituição humana.

Mas, você, leitora, deve se perguntar: o que a caixa de livros tem a ver com o legado da colonização sobre o corpo-território de quem escreve este presente artigo? Vejo uma encruzilhada de possibilidades viáveis para responder tal inquietação. Contudo, peço licença a Exu, dono dos caminhos, para trilhar a via explicativa que tem como territorialidade o campo educacional e como as diásporas africanas, com toda a violência estrutural, conseguem coexistir dentro dos espaços de formação escolar. Não somente a partir das violências, mas por elas também, é que construo a ponte entre a caixa de livros com as subjetividades do meu corpo-território. A subalternização é quem dá o tom dos livros didáticos e isto tem correlação direta com os valores que atribuímos sobre nossas corporalidades, assim como lançamos leituras acerca das outras existências. Ou seja, subalternidades são naturalizadas nas escolas e isso repercute em nossas construções individuais e coletivas.

Por conta disso, após folhear algumas páginas dos livros didáticos, resolvi guardá-los. A colonialidade se apresenta desde as primeiras páginas, nas imagens degradantes dos negros e negras escravizados, na semiótica de inferiorização dos povos originários das Américas. Nesta rápida explanação já se evidencia de que forma as colonialidades do poder são articuladas para credibilizar as ideologias do sistema-mundo moderno (BALLESTRIN, 2013). Ao mesmo passo, verificamos que as colonialidades de gênero e sexualidades são invisibilizadas ou assumem um repertório hierárquico inferior aos elementos gráficos e gramaticais que reforçam a relevância do homem branco, heterossexual, cristão e capitalista. Tudo que está fora desse padrão tem sido apagado ou depreciado pelo sistema político pautado na branquitude (BENTO, 2002) e na heterossexualidade (OCHY, 2013).

Após este caminho, tendo guardado os livros da educação básica, me questiono: E como tem sido a discussão das colonialidades na tessitura dos corpos-territórios dos futuros/as educadores e educadoras? Como a universidade tem problematizado o cimento eurocêntrico (LUZ, 2013) que a fundou e ainda a legitima? Discorrer sobre tais questionamentos é pujante para pensar a minha própria caminhada como um educador que tem parte da profissionalização inventada pelo chão da escola pública e que nos últimos quatro anos vem se des-constituindo como um ser docente-gay-cisgênero.

Ao demarcar a minha sexualidade, não busco findá-la no campo do identitarismo, mas a exponho como uma estratégia de evidenciar que professores/as gays, lésbicas, trans e travestis existem, produzem ciência, criam políticas de resistências contra as colonialidades. Além disso, tensionar a política identitária muito bem estruturada pelo homem branco ocidental (GROSFOGUEL, 2011) que se reivindica universal ao apagar as epistemologias das mulheres, das populações negras, indígenas e das representatividades LGBT + .

Com isso, por ser um educador-gay, que intenta decolonizar o próprio corpo-território e consequentemente os espaços de poder pelos quais transito, o que inclui as salas de aula da universidade que trabalho, é que decidi escrever este artigo a partir do seguinte suleamento: como o encontro entre um corpo-território- 
educador-gay e um corpo-território-educanda-sapatão-preta pode criar um giro decolonial aquilombado? Trago uma experiência que retira do professor a centralidade da construção do conhecimento na sala de aula. Se a educação é o encontro de pessoas diferentes no mesmo espaço, não é cabível que se instale um monólogo e desperdice todas as outras potências que cada um traz no seu corpo-território que deve ser compreendido como um texto vivo e não como um objeto a ser colonizado (KILOMBA, 2019).

Dessa forma, nas próximas seções vou abordar como se deu o meu encontro com a educanda-sapatão-preta, que aqui será chamada de Preta, nome fictício escolhido pela própria educanda. Pretendo com este escrito relatar que a sala de aula pode reverberar as políticas do encobrimento do outro (DUSSEL, 1993) como também podem se constituir como lócus de políticas educacionais criadas pelas escrevivências (EVARISTO, 2008) dos grupos subalternizados.

\section{Na terra estrangeira me fortaleci com a decolonialidade}

Iniciamos nosso bate papo abrindo uma caixa cheia de livros colonizadores e a partir de agora abriremos uma outra caixa que também elucida uma série de colonialidades, mas que em alguns momentos pulsa por um descontrole ao pisar em terras estrangeiras: a Universidade Federal da Bahia - UFBA. Estabeleço a UFBA como uma terra estrangeira por ser uma localidade que no imaginário de muitos baianos, que me incluo, é inimaginável se perceber dentro das relações de poder desta instituição. No meu caso, filho de trabalhadores analfabetos, furei a bolha e realizei um doutorado em Educação na referida instituição.

Ao abrir a caixa da minha trajetória busco compartilhar com os meus pares que nossos percursos pelos espaços do poder hegemônico é possível e que os títulos alcançados não podem ser compreendidos como uma conquista individual e egocêntrica. A cada degrau que um subalternizado consegue subir precisa ter a dimensão coletiva, territorial, política e propositiva. Por isso, pautar a nossa escrevivência por vias decoloniais é fecundo para uma escrita localizada (HARAWAY, 1995), a qual nos instrumentaliza a perspectivar referências teóricas que atendam nossas transgressões, apontem o que nos implica e sustentem tecnologicamente posicionamentos de desobediência epistêmica (MIGNOLO, 2008).

Saio do meu território de nascença e formação acadêmica, a cidade de Feira de Santana, interior da Bahia. Conhecida como o maior entroncamento rodoviário do Norte-Nordeste brasileiro, que no meu vocabulário substituo entroncamento por encruzilhadas, já que meu corpo-território busca uma gramática de leitura do mundo por valores afro-brasileiros e, se estradas se cruzam com diversas vias, só consigo enxergar caminhos de possibilidades. E uma dessas estradas liga minha terra natal à capital Salvador.

Busquei o doutoramento em Educação na UFBA por acreditar que esta titulação poderia abrir muitas portas profissionais e ao mesmo tempo como um ato político de ocupação de espaços universitários enrijecidos aos desejos dos subalternizados. Cheguei no primeiro dia de aula, olhei para os meus colegas e verifiquei o seguinte dado: mais de $90 \%$ brancos e docentes de universidades públicas brasileiras, maior percentual de homens, faixa etária superior aos 35 anos, todos e todas performatizavam a heteronormatividade, pesquisas que não dialogavam com temáticas subalternizadas, entre outros elementos específicos da razão metonímica (SANTOS, 2002). Neste cenário, me encontrava como um homem gay e cisgênero, pardo/preto para alguns e branco para outros, desempregado, com 27 anos e um pré-projeto de pesquisa sobre educação corporal e saberes afro-brasileiros feito com um referencial bibliográfico, em sua maior ordem, por vias eurocêntricas.

A cada aula um novo repertório colonizador se apresentava. Desde a forma como deveríamos nos vestir, o vocabulário acadêmico preciso, perpassando pelas indicações bibliográficas para os próximos encontros, como as falas que me diziam para conduzir os meus estudos por concepções marxistas, estruturalistas, pós-modernas e nunca como uma ruptura epistemológica que fragmentasse as colonialidades. Nessas disputas de posicionamentos e grupos de pesquisas, os critérios de avaliação das agências de fomentos de pesquisa eram as principais norteadoras dos scores a serem alcançados. 
$\mathrm{Na}$ terra estrangeira tive muito medo e por diversas vezes me questionei se aquele espaço era meu e se deveria continuar a enfrentar diariamente tais conflitos. Neste mesmo período, em estudos solitários, descobri a abordagem Decolonial a partir das Epistemologias do Sul. Como quem tinha fome, devorei tudo que cruzava minhas pesquisas virtuais. Sentia na linha Decolonial um conforto e um acolhimento não repercutidos ou invisibilizados na academia. Encontrar a decolonialidade durante o doutoramento significou um fortalecimento dos meus ideais de coletividade ao passo de entender por quais motivos muito do que solidifica as estruturas das universidades atendem aos valores de um mundo com ênfase no heteropatriarcado branco e capitalista.

A decolonialidade chega como uma bússola que me ajudou a seguir um outro caminho, mas sem abrir mão de perfilar por dentro da universidade, aprender as tecnologias hegemônicas, ter a formação teórica eurocêntrica, traduzir inicialmente para o meu próprio corpo-território e devolver para o mundo o que de fato atende aos interesses coletivos dos subalternizados. A decolonialidade me ensinou que a universidade é um polo de produção do conhecimento sobre as teias científicas dos oprimidos, que a universidade tem sido utilizada há séculos para usurpar os conhecimentos dos povos tradicionais e abastecer os cofres da burguesia racista. Isto regado aos banquetes das casas grandes que a cada luxuosa refeição vibra com a certeza de que o futuro continuará representando as tramas do sistema-mundo moderno.

Por aprender que a branquitude e o heteropatriarcado acadêmico se estabelece em contrabandear e batizar com outras nomenclaturas as ciências subalternizadas, decido utilizar este caminho, mas com uma diferença ética: apontar a origem real dos conceitos utilizados em minha pesquisa. Destarte, reescrevo todo o meu projeto de pesquisa com uma problemática que busca investigar a constituição do corpo-território dos/as futuros/as professores e professoras em Geografia da UFBA por lentes afro-brasileiras. Concomitantemente, participei da seleção para professor substituto da Faculdade de Educação (FACED/UFBA), o mesmo espaço no qual realizava o doutoramento, sou aprovado e inicio a docência em turmas de Estágio Supervisionado em Geografia. Em buscas dos documentos oficiais, tais como ementas e projeto político do curso, não existem propostas discursivas sobre as temáticas dos povos subalternizados, sobretudo, no que tange às contribuições epistemológicas dos impérios africanos e dos valores civilizatórios afro-brasileiros. Estas ausências, não podem ser compreendidas como um caso isolado ou uma falta de atenção. São lacunas criadas e mantidas pelas colonialidades para garantir um projeto de universidade para o embranquecimento, como aponta a pesquisadora Narcimária Luz (2000, p. 38):

Ergue-se, aí, uma pedagogia do embranquecimento que, mediante a comunicação escrita, exigirá um corpo adaptado aos valores ocidentais e submisso a uma disciplina incessante, individualizando-o, docilizando-o e o adestrando-o em função de um espaço e tempo fincados em paradigmas positivista, produtivistas e ascéticos, organizadores do sistema social da modernidade.

$\mathrm{Na}$ abordagem decolonial, a pedagogia do embranquecimento não existe sem a pedagogia do heteropatriarcado racista, a qual estabelece um perfil acadêmico e se mantém com base no epistemicídio científico e racial (CARNEIRO, 2005). Por isso, a decolonialidade tem sido imprescindível na ressignificação do meu olhar acerca de todos os espaços que consigo circular. Se antes a minha leitura pautava-se apenas sobre questões de raça, ocorreu vários acréscimos sobre as imbricações das subalternidades de gênero, sexualidade e territórios. Nestes veios, ao assumir a condição de professor substituto na FACED/UFBA e verificar ausências de políticas contra coloniais é que, mesmo em auto decolonização, decido propor aos educandos e educandas uma outra configuração para o componente curricular do Estágio Supervisionado em Geografia.

Pensar esta outra configuração reverberou na tessitura da minha tese de doutoramento com o título Trocas de peles no Atiba-Geo: proposições decoloniais e afro-brasileiras na invenção do corpo-território docente (MIRANDA, 2019). Chegar na terra estrangeira, fortalecer o meu corpo-território e finalizar com a entrega de uma produção textual só foi possível por ter encontrado ao longo do caminho pessoas aliadas, dentre elas a Preta. Sobre este encontro, aquilombado (NASCIMENTO, 2002), irei discorrer na próxima seção. 


\section{Decolonialidade e Quilombos}

Não existe Decolonialidade sem a presença dos Quilombos contemporâneos. Afirmo isso por acreditar que os encontros entre os grupos subalternizados, que se apoiam, representam um continuum ancestral (SODRÉ, 2003) imprescindível para a materialização de uma esfera cosmogônica que não se restringe à resistência cultural, mas que amplia para uma esfera política sempre existente na América Latina. Ou seja, Decolonialidade precisa ser reafirmada como um projeto político coletivo de implosão das edificações coloniais encabeçado pelos corpos-territórios subalternizados.

O fronte de disputas em África se denominava Kilombo e teve suas reinvenções no Brasil (NASCIMENTO, 1982). Tais continuums foram sendo alimentados ao longo da história marginalizada dos povos colonizados na América, o que permitiu em 2020 a escrita do seguinte poema de autoria de Conceição Evaristo:

É tempo de caminhar em fingido silêncio,

e buscar o momento certo do grito,

aparentar fechar um olho evitando o cisco

e abrir escancaradamente o outro.

É tempo de fazer os ouvidos moucos

para os vazios lero-leros,

e cuidar dos passos assuntando as vias

ir se vigiando atento, que o buraco é fundo.

É tempo de ninguém se soltar de ninguém,

mas olhar fundo na palma aberta

a alma de quem lhe oferece o gesto.

O laçar de mãos não pode ser algema

e sim acertada tática, necessário esquema.

É tempo de formar novos quilombos,

em qualquer lugar que estejamos,

e que venham os dias futuros, salve 2020,

a mística quilombola persiste afirmando:

"a liberdade é uma luta constante"

(EVARISTO, 2020).

Em 2020, Conceição Evaristo lançou ao mundo, através da literatura, o que nós, corpo-territórios subalternizados estamos ancestralmente a realimentar: continuum quilombola. E foi justamente este valor civilizatório advindo de África que proporcionou o meu encontro com Preta e o nosso fortalecimento dentro da terra estrangeira. Por dois anos, eu na condição de educador e Preta como discente de Licenciatura em Geografia, atravessamos quatro momentos obrigatórios dos Estágio Supervisionados em Geografia.

Os encontros foram transformados na tese de doutoramento em Educação e seguiu a Sociopoética (GAUTHIER, 1999; ADAD, 2014), uma metodologia de pesquisa que compreende os participantes como copesquisadores e não como objetos a serem pesquisados. Além disso, esta metodologia acredita na potên- 
cia do corpo como um dispositivo criador de conceitos que partem das experiências do cotidiano da vida. Portanto, o meu encontro com Preta esteve atrelado a constituição docente e ao mesmo tempo como uma pesquisa de doutorado. A Seguir, refletirei sobre um dos momentos da pesquisa que batizei como: Giro Decolonial Aquilombado.

\section{Giro Decolonial Aquilombado}

Giro, de onde eu venho, significa sair da linearidade, perder o norte, abalar estruturas, rodar nas ventanias e construir um outro caminho. Então, o encontro de um educador-gay com uma educanda-sapatão-preta que pautam suas identidades e coletivamente as implicam a repensar a estrutura do sistema-mundo moderno constrói um giro decolonial aquilombado dentro da formação docente, que atravessa a terra estrangeira.

Em um dos momentos da pesquisa, precisei dialogar individualmente com Preta. Marcamos na FACED/ UFBA. Preta chegou no horário acordado. Fui ao seu encontro no pátio central. Nossos corpos se abraçaram e por alguns segundos sentimos a energia do outro. Convidei-a para me acompanhar até a sala de aula. Ao entrar no espaço da atividade falei com que gostaria que ela retirasse a sandália e sentasse comigo sobre os colchonetes no chão. Prontamente atendeu o meu pedido e ficamos de frente um para o outro. Expliquei a proposta da atividade daquele encontro e solicitei que ela se levantasse, fosse no canto da sala indicado e pegasse um dos escudos ${ }^{1}$ que estavam espalhados sobre o chão.

A copesquisadora, aqui ela passa a assumir esta condição, retornou com um dos escudos, precisamente com o material do copesquisador Peão ${ }^{2}$, e novamente sentou sobre o colchonete. Identifiquei que ela escolheu o escudo produzido por outro copesquisador. Perguntei se o escudo era o dela e por qual motivo teria selecionado aquele para iniciar o nosso diálogo. A resposta partiu da análise rápida feita por ela em relação aos desenhos traçados: "achei que ele tem elementos que gosto. Esse desenho circular. A aprendizagem em círculo que é algo que eu gosto". Sobre a questão da circularidade por diversas vezes trabalhamos os valores civilizatórios afro-brasileiros, no qual o círculo se constitui como um dos valores:

A questão do círculo, da roda, da circularidade tem uma profunda marca nas manifestações culturais afro-brasileiras, como a roda de samba, a roda de capoeira, as legendárias conversas ao redor da fogueira... No candomblé, os iniciados rodam/dançam durante alguns rituais ou festas. Com o círculo, o começo e o fim se imbricam, as hierarquias, em algumas dimensões, podem circular ou mudar de lugar, a energia transita num círculo de poder e saber que não se fecha nem se cristaliza, mas gira, circula, transfere-se (TRINDADE, 2006, p. 98).

Encontrar na narrativa da copesquisadora Preta um dos valores civilizatórios trabalhados em sala de aula nos indica que alguns elementos do processo formativo chegaram aos seus sentidos e permaneceram. Com isso, não afirmo que a compreensão da copesquisadora sobre circularidade se deu exclusivamente no Estágio Supervisionado ou que não seria em outros espaços que o seu olhar sobre a temática circular se construiu. Apenas elucido que a forma como articulamos a Educação Geográfica esteve a todo tempo pautada nas trocas de energias que uma roda de diálogos pode consubstanciar. Mesmo assim, voltei a questionar se ela poderia apontar como se deu a sua concepção de circularidade e disse:

Então, de teoria mesmo que eu me lembre éo texto de Boaventura, aquele que a gente debateu (título do texto: Para uma sociologia das ausências e uma sociologia das emergências"). E também a ACCS de Pedrão (Professor Pedro Abib) que era muito isso. Mas, de teoria mesmo, além das coisas da vida e da rua, foi o texto de Boaventura. Além das coisas que fa-

1 Escudos construídos em outro momento da pesquisa, onde os copesquisadores desenharam a partir de algumas provocações.

2 Outro corpo-território-educando que participou da pesquisa de doutoramento. 
zíamos nas nossas aulas, que você fazia propostas, das atividades que sempre eram em roda, o movimento de uma roda. E pra mim circularidade também tem hoje uma relação com o tempo, né? Me lembro de chegar muito inquieta na sua aula porque Pedrão falava muito de tempo circular e como a gente não tinha leitura e chegar na aula pra discutir Boaventura e ficar: por favor, eu quero entender o que o tempo circular! Enfim, no início não seria pela circularidade, mas pela relação entre os indivíduos.

Podemos verificar que a formação universitária, mesmo que em apenas dois componentes curriculares um obrigatório e o outro optativo, contribuiu para inquietar o corpo-território de Preta e apresentar durante a formação da sua identidade docente os valores civilizatórios afro-brasileiros. As memórias vasculhadas para responder aos meus questionamentos transporta Preta às salas de aulas da UFBA em semestres concluídos.

Ainda sobre a sua formação docente, lanço à copesquisadora a seguinte provocação: Você acha que na formação da Educação Geográfica a gente precisa falar sobre circularidade?

Consigo ver, sim. Vou tentar elaborar. Primeiro: na Educação eu já acho que isso é necessário. Já que estamos falando de sujeitos que estão se construindo enquanto agentes, pessoas que vão de algum modo atuar na sociedade. Em Geografia...eu acredito que se a gente tá falando de sociedade, a gente tá falando de uma relação...primeiro a gente se desloca da natureza, a gente se separa porque para a perspectiva colonial isso é necessário, é estratégico. Mas, o pensar circular, o pensar roda, o pensar o contato, pra mim é pensar a sociedade. Eu não sei se consigo descrever isso porque na minha cabeça faz tanto sentido que as vezes não consigo traduzir isso. Mas..., a cada momento que a gente vai avançando na compreensão de como o sujeito se relaciona, mais a gente entende como tudo aquilo ali vai circulando. Inclusive os tempos é como ondas...eu vim pra cá pensando nisso, nos movimentos que o tempo faz e como a gente muda o passado a medida que a gente avança. Enfim, eu acho que a própria Geografia a medida que ela avança ela também muda o passado, pois as interpretações que a gente de Geografia antes hoje são desconstruídas. Pensar gênero na Geografia que antes era algo impensável, renegado, os sujeitos eram apenas machos, brancos, o indivíduo era um ser antrópico. Mas, agora a gente pode voltar no processo e dizer que não era bem assim porque tem outros elementos.

Nas primeiras falas de Preta destacou a sua relação com a teoria acadêmica e por quais caminhos construiu academicamente o seu olhar sobre circularidade. Ao ser provocada sobre o referido valor civilizatório na Educação Geográfica prontamente responde que a discussão não se restringe ao fazer geográfico e que o mesmo deve ser ter presença na Educação como todo. Essa afirmação dialoga com a perspectiva de corpo-território-decolonial (MIRANDA, 2019) que vislumbra rachaduras no currículo da escola por compreender que o valor civilizatório em voga traz para as relações humanas o trato com as alteridades, onde a circularidade transfere entre os corpos as Energia Vital:

É uma dimensão interessante, na medida em que revela a circularidade da vida, bem como a sua amplidão. Tudo tem energia vital, é sagrado e está em interação: planta, água, pedra, gente, bicho, ar, tempo. Todos os elementos se relacionam entre si e sofrem influência uns dos outros. Aqueles que conhecem o poder dessa energia vital já compreendiam, bem antes das pesquisas científicas de Lavoisier, que "na natureza tudo se transforma" (TRINDADE, 2006, p. 98).

A Energia Vital é outro valor civilizatório afro-brasileiro que também esteve presente nas discussões do componente curricular, sobretudo, quando abordamos a necessidade do educador e da educadora compreender que as trocas de experiências com os seus alunos é um ato de valorizar a cosmopercepção (OYĚWŨMÍ, 1997) de cada indivíduo. A interação entre todos os elementos da Terra é o que fomenta o estudo da ciência 
geográfica, ou seja, historicamente a geografia se preocupa em produzir sobre a relação homem-natureza-homem e isso já se configurava como uma prática habitual dos africanos muito antes das diásporas provocadas pela colonização europeia em África. Portanto, podemos constatar que a Energia Vital valorizada em África e repercutida nas territorialidades afro-brasileiras podem potencializar as produções geográficas em sua complexidade de análises.

Para o professor Milton Santos (2006), a relação homem-natureza precisa ser pensada com imbricações e um jogo não hierárquico. Outro ponto muito relevante, quando a Preta nos diz como podemos nos tornar responsáveis por voltar no tempo e reconstruir outras histórias. Histórias alicerçadas em veios universais precisam ter as suas imposições fissuradas. Ao criticar a perspectiva colonial ela se insere na centralidade do corpo-território-decolonial, o qual não aceita o epistemicídio e busca estratégias para traçar rotas que evidenciem temáticas ausentes e/ou de pouca expressão na formação docente em geografia, por exemplo, gênero e questões étnico-raciais.

A nossa conversação ganhou fôlego e dentro disso o princípio da Sociopoética, trabalho com grupos de resistências. Acredito que a presença do discurso de gênero, raça, etnia e sexualidade seja recorrente na oralidade de Preta por ela ter construído um corpo-território-decolonial consciente com os seus marcadores sociais e de que forma tais questões da sua corporeidade são interpretadas socialmente, posto que Preta se coloca: "Mulher negra e sapatão". Perante essa demarcação de gênero e raça associadas a circularidade e energia vital, lancei outra inquietação: Qual o grupo social ou qual epistemologia te leva a valorizar a circularidade e contestar a colonialidade? Um pouco antes de completar a inquietação ela responde:

Ahhh, é a população negra. Pra mim é a minha raiz mesmo e não tem como me separar disso. Hoje em dia eu tenho pensado muito no Candomblé. Eu já tenho uma relação como Candomblé há algum tempo. Recentemente conversando com uma amiga ela me falou sobre o Não-Tempo. Um termo que eu não conhecia...Como que o Terreiro, quando você está em uma festa no Terreiro aquilo ali te leva pra uma relação com o tempo completamente diferente do tempo que a gente tem no dia a dia. E isso, pra mim, também é pensar a sociedade. Pensar Candomblé é pensar a sociedade, pensar a circularidade. É pensar em como há a relação com a natureza e como ela pode se diferenciar a depender das relação com as crenças. O pensamento eurocêntrico separa (homem e natureza) e nega a existência.

No ato de atender à minha provocação, a copesquisadora lança de corpo todo as expressões: população negra; Candomblé; Terreiro; Não-tempo. Pergunto se ela é iniciada em alguma religião de matriz africana e para a minha surpresa escuto um não acompanhado de uma possibilidade muito próxima para que o ritual de iniciação se concretize. A copesquisadora utiliza, mesmo que não exponha o termo, outro valor civilizatório abordado em nossas aulas, a Ancestralidade.

O passado, a História, a sabedoria, os olhos dos/das mais velhos/as tomam uma enorme dimensão de saber-poder, de quem traz o legado, de quem foi e é testemunha da História e também sobrevivente. A dimensão ancestral carrega o mistério da vida, da transcendência (TRINDADE, 2006, p. 100).

Compreender a potência da Ancestralidade pode levar o indivíduo a fortalecer o corpo-território-decolonial, ao passo de que descamar as epistemologias eurocêntricas para abrir espaços para as epistemologias advindas da ancestralidade é um encontro com a memória do seu povo, dos mais velhos, isso para quem se coloca no lugar de pertencimento com as populações negras. Ancestralidade se relaciona com o princípio sociopoético da espiritualidade, pois transcende o sentido da visão ocidental, entra na esfera do indecifrável para a cosmovisão eurocêntrica de civilidade.

Em seguida, pedi que mais uma vez ela se levantasse e tentasse identificar entre os outros três escudos qual seria o seu e ela retorna com a sua produção. Analisamos em parceria os desenhos e destinei um tempo 
para que observasse com calma o que ela rabiscou em cada um dos quadrantes. Pedi para colocar os dois escudos no chão e que ela direcionasse o seu olhar sensível para a produção de Peão e destacasse um símbolo que ela também desenharia. Olhou com atenção e apontou para o quadrante em que estava projetado um tambor e o mapa da África.

A escolha por dois símbolos das culturas negras repercutiu nas minhas memórias e me fez lembrar do texto "É preciso africanizar a universidade" de autoria da pesquisadora Luz (2013). Assim sendo, retornei a provocar o corpo-território da copesquisadora com uma questão que também me movimenta e me acompanhou: É preciso africanizar o ensino da geografia! Faz sentido para você esta afirmação? Mais uma vez, Preta responde com muita prontidão e certeza do que acredita:

Total. Inclusive pelas negações da questão racial. É pensar que o espaço...como tudo está muito bem demarcado no espaço. A questão racial também foi ignorada pela geografia. Se a gente pensa, tanto a geografia urbana quanto a geografia agrária, tá tudo muito bem-marcado no espaço urbano. A possibilidade de africanizar é pensar isso por uma outra possibilidade, por outra perspectiva. Não é uma perspectiva que pensa: existem divisões, existem desigualdades e para por aí. Existem desigualdades que são de raça, de classe, gênero, de sexo. Enfim, sobretudo quando a decolonialidade está em pauta. É muito necessário.

Pensar por uma outra perspectiva o que intencionalmente tem sido ignorado pela geografia oficial é um convite a trabalhar com o valor civilizatório afro-brasileiro da Memória: "O povo negro carrega uma memória da nossa História que está submersa, escondida pelo racismo, que precisa ser descortinada, desenterrada" (TRINDADE, 2006, p. 99). Desvelar os fetiches opressores da colonialidade está pautada pelo corpo-território-decolonial, para o qual escrever outras geografias só é possível com as corporeidades dos grupos subalternizados.

Conversar com a copesquisadora Preta é ter a experiência de ser afetado por uma mulher negra que teve a oportunidade de trocar de peles várias vezes, seja na academia, seja no cotidiano da cidade ou nos seus trânsitos nas casas de Candomblé. No caso dela, compreendo que as trocas de peles não aconteceram de forma mecânica. Trocar de pele para ela exprime uma transformação na sua condição de ser humano, de cidadã e como isso chega até o seu corpo-território. Por isso, senti o desejo questioná-la se o fato de ter consciência de ser mulher negra e buscar esse lugar de fala pode ajudar no processo de africanização da Educação Geográfica:

A mulher negra é... como ela é criada historicamente dentro da casa branca, mas ela não faz parte da casa branca, né? Ela está ali. Tá dentro, mas ao mesmo tempo está fora. E na universidade a gente chega e é a mesma coisa. A gente está dentro, mas a gente está excluída porque a gente não é colocada no mesmo lugar. As mulheres negras tem uma visão sobre a sociedade que é muito particular porque ao mesmo tempo que a gente compõe a sociedade a gente tá no lugar de opressão que é tão gritante...não medindo opressões, não calculando opressões. A opressão é tão gritante, tão explicita que a gente consegue ter alguns insights sobre a sociedade que só a gente consegue ter porque inevitavelmente a gente vive isso. $\boldsymbol{O}$ nosso corpo vai ter uma memória disso. Então, se eu penso a sociedade por uma outra perspectiva porque eu sou uma mulher negra, é inevitável pensar a geografia por uma outra perspectiva. Quando eu leio os texto desses caras que dizem que são maravilhosos, eu sempre vou encontrar lacunas. Não estão falando sobre mim ali. Existem alguns aspectos que eu consigo enxergar pelas minhas vivencias que estes textos não dão conta. As vezes não é nem que essas pessoas não queiram. As vezes elas nem conseguem enxergar. Não conseguem chegar lá. A construção daquela pessoa não permite ela compreender o dia a dia de uma mulher preta, moradora do Alto das Pombas. Nem conhece uma periferia e as pessoas não se interessam por isso. Enfim, se eu vivo tendo uma outra leitura sobre a sociedade. E se a geografia estuda a sociedade, inevitavelmente vou ter uma outra construção da geografia. 
Ao discorrer sobre a condição da mulher negra e a perspectiva do ensino de geografia, a copesquisadora aponta como viver e sentir o corpo da mulher negra e ter consciência deste lugar é pulsante na construção identitária e política. Ser mulher negra na sociedade brasileira é ser atravessada por muitas opressões, entrar em territórios, vivê-los e dificilmente ser compreendidas como uma corporeidade que tem o potencial epistemológico para ocupar o espaço da universidade.

O corpo que não ocupa o espaço de produção, mas que se inscreve como um corpo-território-decolonial consegue se erguer diante das invisibilidades e criar estratégias contra hegemônicas. Esta ação vem desde os primeiros corpos negros escravizados oriundos das diásporas. Em terras brasileiras reexistiram com a única potência que conseguiram trazer: o seu próprio corpo. A partir disso, criaram vias de mandigar o jogo do colonizador ao passo de restabelecer as suas cosmopercepções de mundo. Dessa forma, corpo se estabelece como outro valor civilizatório afro-brasileiro: "O corpo é vida, é aqui e agora, é potência, possibilidade. Com o corpo se afirma a vida, se vive a existência, individual e coletivamente. Ele traz uma história individual e coletiva, uma memória a ser preservada, inscrita e compartilhada. O corpo conta histórias" (TRINDADE, 2006, p. 98).

Dialogar com Preta após um período sem encontrá-la pessoalmente me deixou intensamente contente. Primeiro, por perceber como ela vem se forjando através dos marcadores interseccionais latentes em sua corporeidade. Assim como, a inserção dos valores civilizatórios afro-brasileiros está sendo repercutida através do seu corpo-território, já que Preta, ao compreender a sua negritude, ter a consciência de classe e viver a sua condição sapatão reflete sobre todos estes polos e faz a leitura de mundo a partir de um caminho que busca legitimar o seu corpo-território-decolonial. No caso preciso de Preta, a marcação racial se destacou desde o início das aulas, por vários diálogos ela destacava a sua condição de mulher negra, mulher preta, a mulher subalternizada.

Conversamos durante 1 h e 12 minutos com intensas trocas de experiências. Olhava para ela e pensava: como é bom encontrar uma professora da Educação Geográfica tão responsável consigo e com os grupos subalternizados. O compartilhamento produzido no dia neste encontro realimentou os posicionamentos do meu corpo-território-decolonial por verificar que mesmo distante e com redes invisíveis existem parceiros e parceiras dispostas a tecer uma Educação Geográfica preocupada com as questões étnico-raciais, de gênero, sexualidade e classe. Isso só é compreendido por quem acredita no continuum quilombola e, tenha a certeza, que a casa grande sabe da potência deste valor ancestral e por isso o silencia para desarticular.

\section{(In)conclusões: esta caika não vamos fechar}

Escrever este texto durante a pandemia da Covid-19 reforça um compromisso com as pautas da abordagem decolonial. Enquanto estou dentro de casa, com o direito à alimentação, moradia, saúde e segurança, muitos dos meus estão entregues às irresponsabilidades dos governantes políticos. Se instalou um show de perversidades que reafirma a necropolítica (MBEMBE,2018).

Mais uma vez, os grupos subalternizados são bombardeados pelas colonialidades advindas das caravelas, em 1492, mas que estão a navegar em 2020 como se o tempo não tivesse, no mínimo, fissurado seus cascos. Contudo, não podemos negligenciar que fissuramos, sim. Porém, nosso trabalho exige maior aquilombamento. E como aquilombar quando a ordem é saber qual a refeição será o privilégio do dia? A fome, a miséria, a exploração são estratégias utilizadas para nos minar, nos cansar, fazer-nos desistir. Perdemos muitos e muitas para o vírus, não somente por conta dele, mas sobretudo, por quem os governantes escolhem exterminar.

Não conseguiria (in)concluir este texto se não fosse com este formato, com este cenário que me preocupa e adoece nossos corpos. Agora, falando precisamente como um professor da rede de educação pública, verificamos nas políticas educacionais um vírus tão letal quanto a Covid-19. Tal analogia não é irresponsável, é necessária. Há quantos séculos estamos provocando o extermínio intelectual de milhares de jovens negros e 
negras que passam pelo chão da escola? Há quantas décadas estamos balizando que estas populações negras sejam automaticamente direcionadas para a mão de obra da elite burguesa-branca-racista?

Falar, escrever, se colocar decolonial não pode ser uma ação de marketing efêmera. A colonialidade não é efêmero, não é o pós, é o agora. Nosso tempo é o agora que se resulta das colonialidades do passado.

Continuemos a nos aquilombar, a perspectivar outras vias de fuga para possibilidades de direito a vida. Terra nenhuma pode ser estrangeira para nós, subalternizados. Enquanto existir outro e outra que acredita no mesmo giro decolonial, continuaremos a re-existir nas Universidades, nas escolas, na política, em todas as esferas da sociedade, posto que em nossos Oris circula o continuum quilombola.

\section{Referências}

ADAD, Shara Jane. H. Costa. A Sociopoética e os cinco princípios: a filosofia dos corpos misturados na pesquisa em educação. In: ADAD, S.H.C.; PETIT, S.H.; SANTOS, I.; GAUTHIER, J. (Orgs.). Tudo que não inventamos é falso: dispositivos artísticos para pesquisar, aprender e ensinar com a sociopoética. 1 ed. Fortaleza: EdUECE, 2014.

BALLESTRIN, Luciana. América Latina e o giro decolonial. Rev. Bras. Ciênc. Polít., n. 11, 2013, pp. 89-117.

BENTO, Maria Aparecida da Silva. Branqueamento e branquitude no Brasil. In: CARONE, Iray; BENTO, Maria Aparecida Silva (orgs). Psicologia social do racismo - estudos sobre branquitude e branqueamento no Brasil. Petrópolis: Vozes, 2002b. p. 25-58.

CARNEIRO, Sueli. A construção do outro como não-ser como fundamento do ser. Tese [doutorado]. São Paulo: USP, 2005 .

DUSSEL, Enrique. 1492: O encobrimento do Outro (a origem do "mito da modernidade"). CLAESEN, Jaime A. (Trad.) Petrópolis: Vozes, 1993.

EVARISTO, Conceição. Escrevivências da afro-brasilidade: história e memória. Releitura, Belo Horizonte, n. 23, 2008.

EVARISTO, Conceição. Tempo de nos aquilombar. Xapuri. 07/01/2020. <https://www.xapuri.info/cultura/tempo-de-nos-aquilombar/> Acesso em: 22 fev. 2020.

GAUTHIER, Jacques. Sociopoética: Encontro entre arte, ciência e democracia na pesquisa em ciências humanas e sociais, enfermagem e educação. Rio de Janeiro: EAN/UFRJ, 1999.

GROSFOGUEL, R. Racismo Epistémico, Islamofobia Epistémica y Ciencias Sociales Coloniales. Tabula Rasa, Colômbia, n. 14, 2011, p. 341-355.

HARAWAY, Donna. Saberes Localizados: a questão da ciência para o feminino e o privilégio da perspectiva parcial. Cadernos Pagu, vol. 5, 1995, p. 7-41.

KILOMBA, G. Memórias da plantação: episódios de racismo cotidiano. Rio de Janeiro: Cobogó, 2019.

LUGONES, María. Colonialidade e gênero. Tabula Rasa. Bogotá, n. 9, p. 73-101, jul-dez, 2008.

LUZ, Narcimária Correia do Patrocínio. Abebe: a criação de novos valores na educação. Salvador: SECNEB, 2000.

LUZ, Narcimária Correia do Patrocínio. É preciso africanizar a universidade. In: MENEZES, J.M.F.; SANTANA, E.C.; AQUINO, M.S. Educação, região e territórios - formas de inclusão e exclusão. 1. ed. Salvador: Edufba, 2013, v. 1, p. 173-199.

MBEMBE, Achille. Necropolítica: biopoder, soberania, estado de exceção, política da morte. SANTINI, Renata. (Trad.). 2a Ed. São Paulo: n-1 edições, 2018.

MIGNOLO, Walter D. Desobediência epistêmica: a opção descolonial e o significado de identidade em política. Cadernos de Letras da UFF - Dossiê: Literatura, língua e identidade, no 34, 2008, p. 287-324.

MIRANDA, Eduardo Oliveira. Trocas de peles no Atiba-Geo: proposições decoloniais e afro-brasileiras na invenção do corpo-território docente. Tese [doutorado]. Salvador: Universidade Federal da Bahia, 2019. 157 f.

NASCIMENTO, Abdias. O Quilombismo. Brasília/Rio de Janeiro: Fundação Cultural Palmares/OR Editor, 2002.

NASCIMENTO, Maria Beatriz. Kilombo e memória comunitária: um estudo de caso. Estudos Afro-Asiáticos. Rio de Janeiro, CEAA/UCAM, n. 6-7, 1982, p. 259-265. 
OCHY, Curiel. La Nación Heterosexual. Análisis del discurso jurídico y régimen heterosexual desde la antropología de la dominación. Bogotá, D.C: Brecha lésbica y en la frontera, 2013.

OYĚWÙMÍ, Oyèrónké . Visualizing the Body: Western Theories and African Subjects in: OYĚWÙMÍ, Oyèrónké . The invention of women: making an African sense of western gender discourses. Minneapolis: University of Minnesota Press, 1997, p. 1-30.

QUIJANO, Aníbal. Colonialidad del poder y clasificación social. In: CASTROGÓMEZ, S.; GROSFOGUEL, R. (Orgs.). El giro decolonial. Reflexiones para una diversidad epistémica más allá del capitalismo global. Bogotá: Universidad Javeriana-Instituto Pensar, Universidad Central-IESCO, Siglo del Hombre Editores, 2007. p. 93-126.

SANTOS, Boaventura de Sousa. Para uma sociologia das ausências e uma sociologia das emergências. Revista Crítica de Ciências Sociais, n. 63, outubro/2002.

SODRÉ, Muniz. O terreiro e a cidade: a forma social negro-brasileira. Petrópolis: Vozes, 2003. 